\title{
Teaching and Development Ideas of Double-row Keyboard Electronic Organ in Colleges and Universities
}

\author{
Liu Xin ${ }^{*}$ \\ Heihe College, Heihe Heilongjiang 164300
}

Keywords: Colleges and universities; Double key keyboard teaching; Development

Abstract: The double-row keyboard electronic organ is different from other musical instruments. It is a comprehensive and expressive electronic instrument. It not only brings people good enjoyment, but also opens up the field of expression of electronic instruments. Especially the double-row keyboard electronic organ music form of expression can express a variety of music types such as classical symphony, jazz, pop music, so some people call it a person's band. Because of its rich expressive force, it is loved by many music lovers.

\section{Introduction}

Throughout the history of the development of double-row keys in China, from the early 1980s to the present more than 20 years, double-row keys have emerged from scratch. From the establishment of double-row keys in some colleges and universities to the opening of this major in more than 30 colleges and universities, we can see that the education of double-row keys has been achieved with the efforts of many teachers. Rapid development. For example, Shanghai Conservatory of Music, Shenyang Conservatory of Music, Central Conservatory of Music, Tianjin Conservatory of Music and other old colleges and universities have played a great role in the development of double-row keys, trained a large number of double-row keyplayers, but also trained a large number of teachers. However, in the course of the development of the double-row keyboard electronic organ for more than 20 years, we also feel that the development of the double-row keyboard electronic organ is difficult, such as the shortage of teachers, the shortage of students, the expensive equipment, the lag of teaching materials and many other factors are affecting and restricting the further development of the double-row keyboard electronic organ. The following is a discussion on teaching materials and teaching methods.

\section{Strengthen Teaching Materials and Further Clarify the Standards of Subject Teaching.}

The textbook construction is an important factor in the development of double-row keyboard electronic organ in normal universities. The textbook construction is very important and a symbol of any subject. Browsing the textbooks used by our art colleges and universities at present, many colleges and universities basically use self-compiled textbooks or other textbooks and music collections independently, but these textbooks are generally limited to the use of the school, not widely promoted, not published and publicly issued, the utilization rate is not high, resulting in a 
great waste of resources. Therefore, it is necessary to compile a set of systematic, complete, universally recognized and widely used authoritative textbooks. This is applicable and valuable to both professional and non professional students. With a systematic textbook, the purpose, content and requirements of teaching are well defined. There are rules to follow in teaching, which can play a role in standardizing teaching and learning.

\section{We Should Pay More Attention to the Atudy of Teaching Methods}

The teaching method is the research teaching method, is a discipline teaching theory elaboration, is according to the pedagogy, the psychology viewpoint explores the teaching some regular questions. At present, the research on the teaching method of double-row keyboard electronic organ is still blank, but the research on the teaching method of double-row keyboard electronic organ will be helpful to the teaching and playing of double-row keyboard electronic organ. Sometimes we can see that some students play dull, some students are full of passion, excluding personal factors, mainly reflected in the guidance of teaching methods. For example, the touch keys of the double row keyboard are different from the keys of the piano. In teaching, teachers may adopt some piano training methods and piano music as a supplement to the technical training, which is worth advocating and developing, but also the electronic piano technical training must grasp and learn from, such as the natural weight of the arm touch the key, elevate the finger and other basic exercises. But the double-row keyboard electronic organ and the piano have essential differences in the principle of sound production, especially in the touch of the key has its special side. If all follow the piano playing method, the electronic piano playing method will be misunderstood, music performance will naturally be dull. Especially when playing some characteristic instruments, such as stringed instruments, brass instruments, woodwind instruments and so on, if we do not understand the characteristics of the instrument and playing methods, it will appear to lack charm, individuality and appeal. The main reason is that there is no in-depth study on the characteristics of the double-row keyboard electronic piano, and the lack of correct guidance on the playing methods of the double-row keyboard electronic piano leads to the randomness of playing. Therefore, the study of the double-row keyboard electronic organ should form a systematic theoretical guidance from the formulation of the syllabus, to the establishment and improvement of teaching methods, so as to make the construction of this subject more perfect.

\section{We Should Strengthen the Training of the Practical Ability of Double Row Keyboard Electronic Organ.}

The study of double row keyboard organ can not just stay in playing several pieces of music learning. We should further strengthen the understanding and application of timbre, rhythm and functional effects.

\subsection{The Production of Timbre and Rhythm}

We are accustomed to using the preset timbre and rhythm directly on the electronic organ, because the timbre and rhythm are already preset enough for us to use, but the question is, when we need to compose a piece of music, how should we design the timbre and rhythm we need, how should we modulate it? This requires more research. And practice. 


\subsection{The Allocation of music}

Music arrangement mainly refers to the harmony arrangement and instrumental method (timbre and rhythm application). The arrangement is the concrete manifestation of the actual expression of the electronic piano. The performance of the electronic piano can not simply stay on playing the music. In fact, the electronic piano has designed so many functions and sound effects that people need to explore its use and show you the control of the instrument. Power. Therefore, the arrangement or accompaniment of harmonies for electronic music is set up.

Considering the application of timbre and rhythm, it becomes the main content of teaching and the ability that every learner must have. But at present, there is such a problem that students can easily accept the existing works and become passive when they come into contact with the actual ability to learn. This is mainly for the following reasons: (1) many of the ready-made works have designed the timbre and rhythm for the performers. Speed and so on, it seems easy to play, without brains.

\subsection{No Pre Designed Works Need to be Played When Playing}

Based on the understanding of the composition, it requires the performer to spend some time thinking about the timbre, rhythm and so on.

It is inert to the study which takes time to think. The reason is that the knowledge of harmony and the method of arranging instruments is too little, and the initiative of conscious practice is not enough. Therefore, while carrying out technical guidance to students, we should emphasize the cultivation of practical and mental abilities.

\subsection{Strengthening of Comprehensive Training}

Comprehensive exercise is an important part of the collective teaching of electronic piano, which includes a variety of basic skills training.

(1) Visual training: The aim is to improve students'visual ability, training the left and right brain to control hands, feet and strain ability. Simultaneous visual exercise It also includes simple transposition exercises.

(2) Playing and singing exercises: it is the organic combination of accompaniment and vocal music, the comprehensive application of vocal music skills and electronic piano skills, requiring students to be able to express while playing and singing, and cultivating students'coordination ability in many aspects.

(3) Improvisation: It is a kind of performance method which mainly depends on the performer's improvisation on the spot, and it is a complex mental skill. It is the comprehensive embodiment of the application ability of the electronic organ.

(Ensemble) training: Ensemble (ensemble) training is the most distinctive teaching content of the collective teaching of electronic organ. All these enable students to fully experience the infinite charm of orchestral ensemble and other instrumental repertoire. It is an important way for us to train and improve students'comprehensive adaptability to meet the needs of teaching conditions.

\section{The Establishment of Double Row Keyboard Electronic Organ Academy.}

The purpose of setting up the Society of Double-row Keyboard and Electronic Orchestra in normal universities is to have an organizer who can organize academic exchanges for everybody. Because there is so little communication in this area, teachers are basically working hard on their own, so many such as information exchange, music exchange, creative exchange, teaching 
exchange, performance exchange and so on are too scarce. If there is an organization, and some professional institutions such as Shanghai Conservatory of Music, Shenyang Conservatory of Music, Central Conservatory of Music, Tianjin Conservatory of Music and so on as the leading, take the lead in organizing some academic exchanges, teaching and observation activities, or hold training courses for the double-row keyboard electronic organ, it will be a huge development and popularization of the double-row keyboard electronic organ. The driving force.

\section{We Should Strongly Support the Development of National Brands.}

Up to now, the double-row keyboard electronic organ has been monopolized by famous foreign brands, and its price is expensive, which seriously restricts the development and popularization of the double-row keyboard electronic organ in China. But now this monopoly will be broken, China's own development and production of double-row electronic piano will finally be born, filling the domestic gap. It will have far-reaching significance for the development and popularization of double row keyboard electronic organ in China. To sum up, although many factors restrict the development of double row keyboard electronic organ. But we also see that the spring of the development of double-row keys is coming. The Seminar on teaching double-row keys and electronic organs held in Shanghai Conservatory of Music on May 30, 2007 is a good start. It has epoch-making significance for the popularization and development of double-row keys and electronic organs in China. At the same time, we should also be soberly aware that to promote and develop the education of double-row keyboard, there are still many things to do, is the duty of many art colleges and universities.

\section{Conclusion}

At present, the development of double-row keyboard is on the rise in Colleges and universities, and more and more schools will open this major. In some schools, double row keys are chosen as elective courses as a general understanding of learning. Some schools as a professional training, from the beginning of school system learning, learning time is four years. Because of the different training objectives, there are different teaching plans, teaching requirements, curriculum standards, teaching materials. But no matter what the conditions are, the spark can start a prairie fire. The present situation can prove everything. So today, I take this opportunity to discuss the development of double-row keyboard electronic organ in Colleges and universities. We hope that the teaching of double row keyboards can make great progress and a bright future.

\section{References}

[1] Li Ting Zi. Application of double row keyboard electronic music in music teaching [D]. Xi'an Conservatory of Music, 2017.

[2] Cui Li Juan. A case study on the teaching status of double-row keyboard electronic organ in Higher Vocational Colleges in Shanxi Province [D].Hebei Normal University, 2016.

[3] Sheffi. Application of piano teaching method in double row keyboard teaching [D]. Hebei Normal University, 2013.

[4] Liu Ying. Exploration of the double-row key teaching mode in music colleges [J].Journal of Mianyang Normal University, 2012, 31 (04): 152-155. 